\title{
Telemonitoring Kadar pH EC dan Suhu untuk Penyehatan Tanah Tercemar Berbasis Web
}

\author{
Rahmana Burhan Rasyidi'1), Farida Arinie Soelistianto ${ }^{2)}$, Koesmarijanto ${ }^{3)}$ \\ 1,2) Program Studi Jaringan Telekomunikasi Digital, \\ Jurussan Teknik Elektro, Politeknik Negeri Malang, Indonesia \\ 3) Program Studi Teknik Telekomunikasi, \\ Jurussan Teknik Elektro, Politeknik Negeri Malang, Indonesia
}

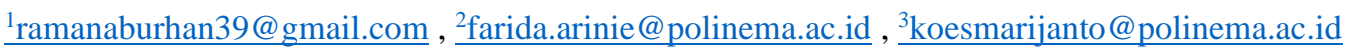

\begin{abstract}
Environmental pollution is the most prominent issue today, along with the increase in population, it causes a lot of garbage piles. A chemical reaction that produces certain gases causes the accumulation of solid waste to rot. The aim of this research is to create a web-based soil health telemonitoring system using EC sensors, pH sensors, and the web. The results of $\mathrm{pH}$ and EC measurements are taken and entered into a database and will be displayed on a web page. The Wemos D1 Mini microcontroller will process the signal read by the sensor and display it on the LCD and Web pages in real time. The results of the application of the system are carried out by plugging the two sensors into the soil to be measured, the results of the data that I took on this land with more colomite were the average EC and the pH on the soil was higher than the soil that was not dominated or had little domination due to the soil that was given dolomite. more will increase the EC and pH of the soil. Based on the results of tests carried out by the EC Soil Sensor and the temperature here can detect soil conductivity with an average value close to $400 \mu \mathrm{s} / \mathrm{cm}$ and an average temperature close to $24-26^{\circ} \mathrm{C}$ because this sensor has calibrated automatically, the pH sensor can detect the pH on the soil evenly $0 \%$ error rate.
\end{abstract}

Keywords - EC sensor, pH sensor, dolomite and landfill.

Abstrak - Pencemaran lingkungan merupakan isu yang paling menonjol saat ini, seiring dengan peningkatan jumlah penduduk menimbulkan banyak nya timbunan sampah. Padatan, lumpur, bubur yang berasal dari proses pengolahan adalah limbah padat hasil buangan industri. Adanya reaksi kimia yang menghasilkan gas tertentu sehingga penimbunan limbah padat ini busuk menyebabkan pencemaran tanah dan polusi udara. Karena tertimbunnya limbah ini dalam jangka waktu lama menyebabkan permukaan tanah menjadi turun salinitasnya. Tujuan dari penelitian ini adalah membuat sistem telemonitoring kesehatan tanah berbasis web dengan sensor EC, sensor pH, dan web. Hasil pengukuran pH dan EC yang diambil dan masuk ke dalam database dan ditampilkan dihalaman web. Mikrokontroler Wemos D1 Mini akan memproses sinyal yang terbaca oleh sensor dan menampilkan pada LCD dan halaman Web secara real time. Hasil penerapan sistem dilakukan dengan cara menancapkan kedua sensor pada tanah yang akan diukur,hasil dari data yang diambil tanah berdolomite lebih banyak ini rata rata EC dan pH pada tanah tersebut lebih tinggi dari pada tanah yang tidak berdolomite atau berdolomite sedikit dikarenakan tanah yang diberi dolomite lebih banyak akan meningkatkan EC dan pH pada tanah tersebut. Berdasarkan hasil pengujian yang dilakukan Sensor Soil EC dan suhu disini dapat mendeteksi konduktivitas tanah dengan nilai rata rata mendekati $400 \mu \mathrm{s} / \mathrm{cm}$ dan suhu rata rata mendekati $24-26^{\circ} \mathrm{C}$ dikarenakan sensor ini sudah mengkalibrasi otomatis, sensor pH dapat mendeteksi pH pada tanah dengan rata rata error $0 \%$.

Kata kunci-Sensor EC, Sensor pH, Dolomit dan Tanah Timbunan Sampah

\section{PENDAHULUAN}

Pencemaran terjadi akibat proses pengambilan, pengolahan dan pemanfaatan sumber daya alam yang menghasilkan sisa (entropi) yang tidak digunakan dan dibuangkarena tidak dibutuhkan pada saat itu. Akibat akumulasi bahan sisa ini maka lingkungan menjadi rusak yang menyebabkan menurunnya kemampuan lingkungan untuk memenuhi kebutuhan hidup manusia bahkan dapat berdampak buruk seperti mengakibatkanpenyakit dan bencana alam[1].

Pencemaran tanah bisa disebabkan limbah domestik, limbah industri, dan limbah pertanian. Timbunan sampah yang berasal dari limbah domestik dapat mengganggu atau mencemari karena lindi (air sampah), bau dan estetika. Timbunan sampah juga menutupi permukaan tanah sehingga tanah tidak bisa dimanfaatkan. Padatan, lumpur, bubur yang berasal dari proses pengolahan adalah limbah 
padat hasil buangan industri. Adanya reaksi kimia yang menghasilkan gas tertentu menyebabkan penimbunan limbah padat ini busuk selain itu pencemaran tanah juga menyebabkan timbulnya bau di sekitarnya. Karena tertimbunnya limbah ini dalam jangka waktu lama menyebabkan permukaan tanah menjadi rusak [2].

Adapun penelitian yang berhubungan dengan kualitas tanah yaitu "Rancang Bangun Alat Ukur Suhu Tanah, Kelembaban Tanah, dan Resistansi" pengguna hanya dapat melihat hasil dari pengujian hanya dari LCD, kelemahan dari sistem ini adalah peneliti hanya menggunakan hasil hanya keluar di LCD dimana sistem ini tidak memberi kemudahan untuk pengguna yang harus bolak balik melihat hasilnya jika rumah sipengguna jauh dari tempat percobaan, dikarenakan rumah setiap pengguna tidak selalu dekat dengan tempat percobaan. Dan kelemahan kedua dari sistem ini adalah tidak melihatkan kadar polutan karena mengetahui polutan di tanah sangat penting bagi orang yang akan menanam tumbuhan jika pengguna tidak tahu berapa kadar polutan di tanah itu hasil panen menjadi tidak maksimal [3]-[5].

Hasil dari penelitian ini dapat membantu konsumen untuk mendapatkan informasi mengenai polutan yang ada pada tanah, kelembaban itu sendiri dan mempermudah konsumen untuk melihat berapa kadar polutan di tanah itu, sehingga konsumen tidak perlu kawatir jika ingin bercocok tanam di daerah itu. Maka dibuat alat monitoring polutan dan kelembaban berbasis internet of things, untuk mengetahui polutan dan kelembapannya dengan sensor soil EC(Electrical Conductivity) akan mendeteksi berapa kadar polutan di tanah kemudian data yang telah didapatkan dikirim ke server. Data yang telah dikirim kemudian disimpan di database dan dikirim secara real time ke web. Sehingga user dapat mengetahui informasi melalui web. Kelebihan lain dari sistem ini juga menggunakan LCD dimana komponen ini sangat berguna untuk mempermudah pengguna, jadi sebagai pengguna akan tetap bisa memonitoring penggunaan dan mengetahui konduktivitas yang terdapat pada tanah yang di ukur.

\section{METODE}

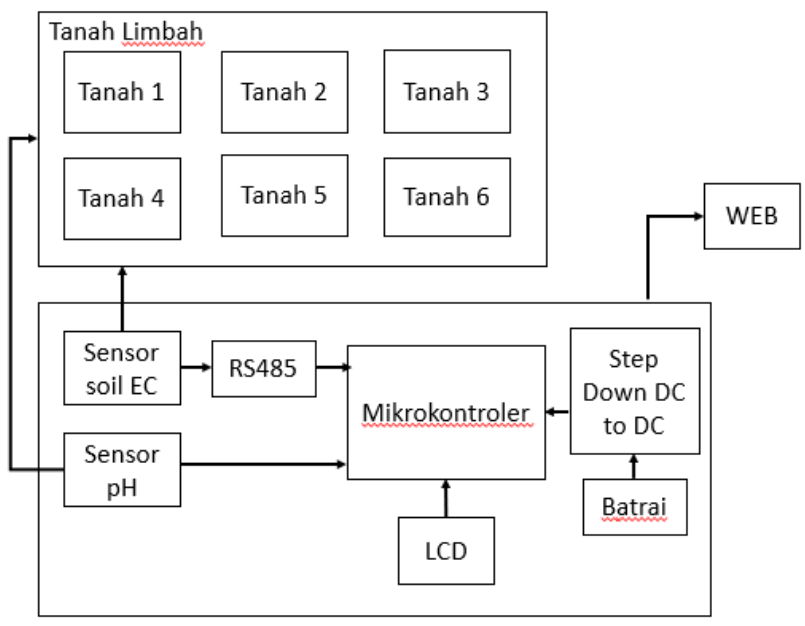

Gambar 1. Blok diagram
Gambar 1 blok diagram perancangan sistem akan dijelaskan proses kerja sistem yang dilakukan selama penelitian, keterangan dari Gambar 1 sebagai berikut : 3 buah sampel tanah dalam polybag berdasarkan campuran tanah yang diberikan dan perlakuan yang berbeda tiap polybacknya tanah pertama manggunakan tanah limbah dan kompos, tanah kedua menggunakan tanah limbah, kompos, dan dolomite $1 / 2 \mathrm{~kg}$ tanah yang ketiga menggunakan dolomite $1 \mathrm{~kg}$, setelah itu deteksi kadar $\mathrm{pH}$ nya menggunakan sensor $\mathrm{pH}$ tanah, diukur suhu dan EC(electrical conductivity) nya menggunakan sensor EC(electrical conductivity),cara kerja sensor $\mathrm{pH}$ nya adalah baca data analog yang dihasilkam sensor $\mathrm{pH}$ kemudian data analog dimasukan ke dalam rumus sesuai datasheet lalu hasil keluaran dari sensor akan ketemu hasil nya, cara kerja sensor EC(electrical conductivity) dihubungkan ke modul RS485 to ttl lalu input register sesuai dngan datasheet kemudian akan mendapatkan respon dari sensor kemudian dimasukan kedalam rumus sesuai dengan datasheet lalu akan keluar hasil nya setelah hasil ketemu hasil akan dimasukkan kedalam variabel untuk dikirimkan ke database lalu web akan membaca data pada database. Alat pengukur tersebut dapat menyimpan dan mentransfer data hasil pengukuran langsung yang dapat diakses melalui web. Alat pengukur tersebut juga dilengkapi dengan display oled LCD yang menampilkan kadar limbah dan kadar ph di tanah jika tidak ingin membuka halaman web dan menghemat kuota.

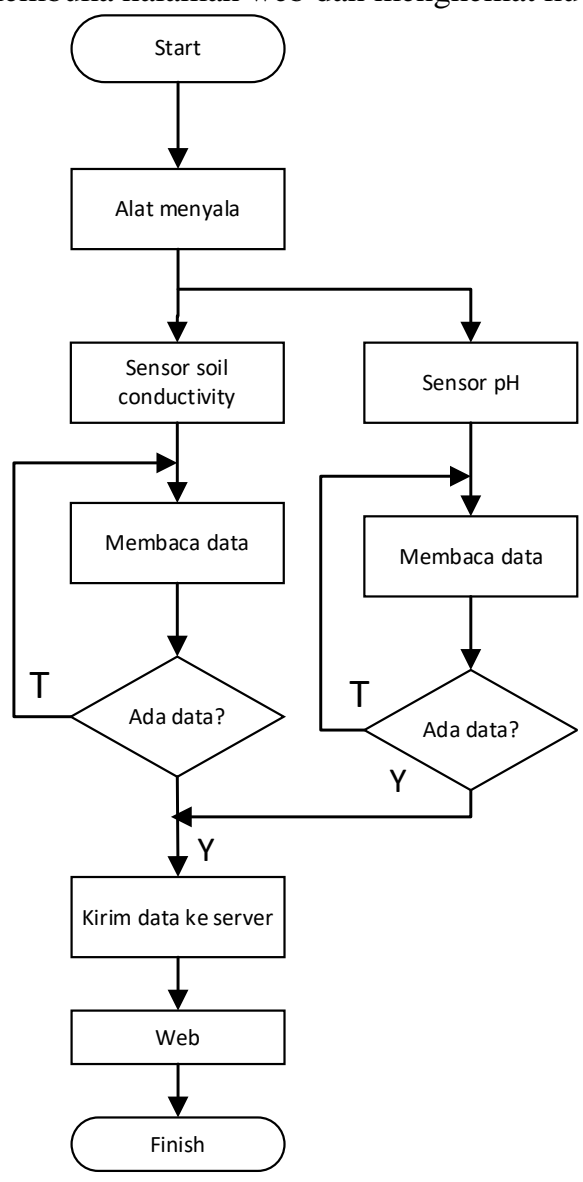

Gambar 2. Flowchart alur kerja program 
Pada saat alat menyala maka sensor akan mendeteksi kadar $\mathrm{pH}$ nya menggunakan sensor $\mathrm{pH}$ tanah, diukur suhu dan EC(electrical conductivity) nya menggunakan sensor EC cara kerja sensor $\mathrm{pH}$ nya adalah baca data analog yang dihasilkam sensor $\mathrm{pH}$ kemudian data analog dimasukan ke dalam rumus sesuai datasheet lalu hasil keluaran dari sensor, cara kerja sensor EC dihubungkan ke modul RS485 to ttl lalu input register sesuai dengan datasheet kemudian akan mendapatkan respon dari sensor kemudian dimasukan kedalam rumus sesuai dengan datasheet lalu hasil akan dimasukkan kedalam variable untuk dikirimkan ke database lalu web akan membaca data di database. Alat pengukur dapat menyimpan dan mentransfer data hasil pengukuran langsung dapat diakses melalui web.

TABEL I

TINGKAT KEASAMAN TANAH

\begin{tabular}{cc}
\hline $\mathbf{p H}$ & Kelas \\
\hline$<4,5$ & Sangat masam \\
$4,5-5,5$ & Masam \\
$5,6-6,5$ & Agak masam \\
$6,6-7,5$ & Netral \\
$7,6-8,5$ & Agak alkalis \\
$>8,5$ & Alkalis \\
\hline
\end{tabular}

TABEL II

TINGKAT SUHU TANAH

\begin{tabular}{cc}
\hline Suhu & Keterangan \\
\hline$<20$ & Buruk \\
20 & Baik \\
$24-26$ & Sangat baik \\
27 & Baik \\
$28>$ & Buruk \\
\hline
\end{tabular}

\section{HASIL DAN PEMBAHASAN}

Tahap pengujian ini terdiri dari prosedur pengujian yang akan didapatkan data hasil pengujian sesuai parameter.

TABEL III

HASIL PENGUJIAN SENSOR PH

\begin{tabular}{ccccc}
\hline No & Jam & Sensor $\mathrm{pH}$ & $\mathrm{pH} \mathrm{Meter}$ & Error $(\%)$ \\
\hline 1 & 09.00 & 7.0 & 7.0 & 0 \\
2 & 09.30 & 7.0 & 7.0 & 0 \\
3 & 10.00 & 7.0 & 7.0 & 0 \\
4 & 10.30 & 7.0 & 7.0 & 0 \\
5 & 11.00 & 7.0 & 7.0 & 0 \\
6 & 11.30 & 7.0 & 7.0 & 0 \\
7 & 12.00 & 7.0 & 7.0 & 0 \\
8 & 12.30 & 7.0 & 7.0 & 0 \\
9 & 13.00 & 7.0 & 7.0 & 0 \\
10 & 13.30 & 7.0 & 7.0 & 0 \\
\hline
\end{tabular}

Tabel di atas memperlihatkan hasil data yang diperoleh dari sensor $\mathrm{pH}$ tanah dan kemudian dilakukan perhitungan error nilai sensor, dengan $\mathrm{pH}$ meter yang digunakan sebagai referensi untuk mengetahui nilai keakurasian sensor. Berdasarkan hasil pengujian yang telah dilakukan setiap 30 menit sebanyak 10 kali, didapatkan nilai $\mathrm{pH}$ tanah saat kondisi netral pada $\mathrm{pH}$ meter adalah 7 , nilai $\mathrm{pH}$ pada sensor $\mathrm{pH}$ adalah 7, pada table bisa dilihat nilai sensor dengan nilai $\mathrm{pH}$ meter adalah sama hingga menghasilkan nilai error $0 \%$ hingga pengukuran ke 10 dan bisa disimpulkan sensor sudah bagus dan bisa digunakan unttuk mengukur ph tanah.

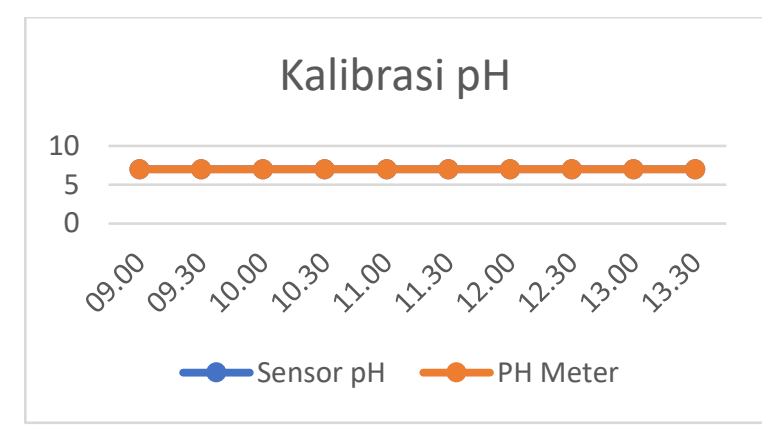

Gambar 2. Grafik kalibrasi sensor $\mathrm{pH}$

Dari grafik diatas diketahui bahwa perbandingan nilai sensor soil moisture dengan soil meter ini memiliki nilai yang sangat berdekatan. Saat pukul 09.00 sensor $\mathrm{pH}$ dapat membaca keadaan $\mathrm{pH}$ tanah dengan baik sampai dengan waktu pukul $13.30 \mathrm{pH}$ meter juga menunjukkan nilai yang sangat berdekatan dengan nilai error $0 \%$. Hal ini ditunjukkan dari bentuk grafik dimana nilai sensor $\mathrm{pH}$ meter dengan sensor $\mathrm{pH}$ berada pada 1 titik garis.

TABEL III

Hasil PENGAMBILAN DATa EC

\begin{tabular}{cccccc}
\hline \multirow{2}{*}{$\begin{array}{c}\text { Hari } \\
\text { ke }\end{array}$} & \multirow{2}{*}{ Jenis tanah } & \multicolumn{4}{c}{ EC $(\boldsymbol{\mu s} / \mathbf{c m})$} \\
\cline { 3 - 6 } & $\mathbf{0 8 : 0 0}$ & $\mathbf{1 0 : 0 0}$ & $\mathbf{1 5 : 0 0}$ & $\mathbf{1 7 : 0 0}$ \\
\hline 1 & & 328 & 306 & 260 & 246 \\
2 & & 289 & 314 & 284 & 290 \\
3 & & 255 & 283 & 258 & 259 \\
4 & Tanah ke 1 & 288 & 240 & 270 & 268 \\
5 & & 249 & 280 & 244 & 263 \\
6 & & 278 & 280 & 285 & 284 \\
7 & & 294 & 277 & 291 & 274 \\
\hline 1 & & 382 & 362 & 360 & 350 \\
2 & & 351 & 381 & 343 & 350 \\
3 & & 375 & 410 & 344 & 371 \\
4 & Tanah ke 2 & 343 & 350 & 393 & 356 \\
5 & & 345 & 382 & 329 & 394 \\
6 & & 345 & 362 & 397 & 338 \\
7 & & 344 & 341 & 368 & 363 \\
\hline 1 & & 409 & 415 & 391 & 373 \\
2 & & 391 & 374 & 379 & 389 \\
3 & & 404 & 382 & 412 & 443 \\
4 & Tanah ke 3 & 431 & 416 & 402 & 403 \\
5 & & 432 & 371 & 351 & 369 \\
6 & & 409 & 370 & 399 & 401 \\
7 & & 413 & 416 & 384 & 395 \\
\hline
\end{tabular}


Data hasil pengukuran pada tabel III ini dilakukan 4 hari sekali pada saat pagi dan sore dengan jam yang sudah ditentukan yaitu pagi pada pukul 08:00 sampai dengan 10:00, sore pada pukul 15:00 sampai dengan 17:00 ketiga tanah hasil dari $\mathrm{pH}$ tanah 1 , tanah 2 , dan tanah 3 berbeda beda tanah 1 hasil nya lebih kecil dari tanah ke 2 dan ke 3 dikarenakan tanah 1 tidak memakai dolomite, tanah 2 lebih kecil dari tanah 3 dikarenakan tanah 2 memakai dolomite hanya $1 \mathrm{~kg}$ sedangkan tanah 3 memakai dolomite $2 \mathrm{~kg}$. Lebih jelasnya bisa dilihat pada grafik hasil pengukuran masing masing tanah.

TABEL IV

HASIL PENGAMBILAN DATA PH

\begin{tabular}{cccccc}
\hline \multirow{2}{*}{$\begin{array}{c}\text { Hari } \\
\text { ke }\end{array}$} & \multirow{2}{*}{ Jenis tanah } & \multicolumn{4}{c}{$\mathbf{p H}$ tanah } \\
\cline { 3 - 6 } & $\mathbf{0 8 : 0 0}$ & $\mathbf{0 8 : 0 0}$ & $\mathbf{0 8 : 0 0}$ & $\mathbf{0 8 : 0 0}$ \\
\hline 1 & 4.32 & 4.78 & 4.89 & 5.11 \\
2 & & 5.12 & 4.78 & 5.19 & 5.22 \\
3 & & 4.63 & 5.33 & 5.02 & 5.18 \\
4 & Tanah ke 1 & 4.95 & 4.64 & 4.34 & 5.34 \\
5 & & 4.54 & 4.85 & 4.23 & 5.32 \\
6 & & 4.87 & 4.34 & 5.22 & 5.22 \\
7 & & 4.85 & 4.78 & 4.96 & 5.25 \\
\hline 1 & & 4.63 & 5.48 & 5.35 & 5.23 \\
2 & & 4.72 & 4.68 & 5.22 & 5.55 \\
3 & & 4.83 & 5.23 & 5.94 & 6.02 \\
4 & Tanah ke 2 & 4.65 & 5.76 & 5.34 & 6.12 \\
5 & & 4.94 & 6.14 & 5.88 & 5.58 \\
6 & & 5.37 & 5.53 & 5.02 & 5.92 \\
7 & & 5.24 & 5.88 & 5.76 & 5.63 \\
\hline 1 & & 6.77 & 6.54 & 6.85 & 7.20 \\
2 & & 6.37 & 6.64 & 6.86 & 7.32 \\
3 & & 6.57 & 6.42 & 6.96 & 7.23 \\
4 & Tanah ke 3 & 6.43 & 6.74 & 6.75 & 7.28 \\
5 & & 5.94 & 6.57 & 6.84 & 7.07 \\
6 & & 6.67 & 6.85 & 6.86 & 7.15 \\
7 & & 6.54 & 6.91 & 6.86 & 7.12 \\
\hline
\end{tabular}

Data hasil pengukuran pada tabel IV ini dilakukan 4 hari sekali pada saat pagi dan sore dengan jam yang sudah ditentukan yaitu pagi pada pukul 08:00 sampai dengan 10:00, sore pada pukul 15:00 sampai dengan 17:00 ketiga tanah hasil dari EC tanah 1, tanah 2, dan tanah 3 berbeda beda tanah 1 hasil nya lebih kecil dari tanah ke 2 dan ke 3 dikarenakan tanah 1 tidak memakai dolomite, tanah 2 lebih kecil dari tanah 3 dikarenakan tanah 2 memakai dolomite hanya $1 \mathrm{~kg}$ sedangkan tanah 3 memakai dolomite $2 \mathrm{~kg}$. Lebih jelasnya bisa dilihat pada grafik hasil pengukuran masing masing tanah.
TABEL V

HASIL PENGUJIAN DELAY

\begin{tabular}{|c|c|}
\hline No & Delay \\
\hline 1 & 0 \\
\hline 2 & 0.000005 \\
\hline 3 & 0.3056 \\
\hline 4 & 0.000006 \\
\hline 5 & 4.331756 \\
\hline 6 & 0.015664 \\
\hline 7 & 0.321926 \\
\hline 8 & 0.000003 \\
\hline 9 & 4.340131 \\
\hline 10 & 0.000023 \\
\hline 11 & 0.312405 \\
\hline 12 & 0.000032 \\
\hline 13 & 4.327213 \\
\hline 14 & 0.310542 \\
\hline 15 & 0.324406 \\
\hline 16 & 4.014836 \\
\hline 17 & 0.015626 \\
\hline 18 & 0.302275 \\
\hline 19 & 0.000003 \\
\hline 20 & 4.997195 \\
\hline 21 & 0.004033 \\
\hline 22 & 0.308501 \\
\hline 23 & 0.008139 \\
\hline 24 & 4.335806 \\
\hline 25 & 0.007969 \\
\hline 26 & 0.310313 \\
\hline 27 & 0.01202 \\
\hline 28 & 4.330444 \\
\hline 29 & 0.00392 \\
\hline 30 & 0.307235 \\
\hline Rata rata & 0.1536175 \\
\hline
\end{tabular}

Delay adalah waktu yang diperlukan suatu paket untuk sampai ke tujuan. Untuk software yang digunakan adalah wireshark. Sampel 30 paket yang akan dicari rata - rata dari delay, paket tersebut diambil pada wireshark yang terdiri dari beberapa paket ketika melakukan livestreaming. Pada gambar 17 merupakan proses perhitungan delay dimana setelah memilih 30 sampel paket maka selanjutnya menjumlahkan semua paket sehingga bisa diperoleh delay rata - rata. Dari perhitungan paket yang dihasilkan rata - rata delay yang diperoleh adalah $0.1536175 \mathrm{~s}$ dapat kita lihat bahwa hasil perhitungan delay sangat kecil. Semakin kecil delay maka akan semakin bagus kualitas suatu panggilan karena tidak akan terjadi keterlambatan informasi. 


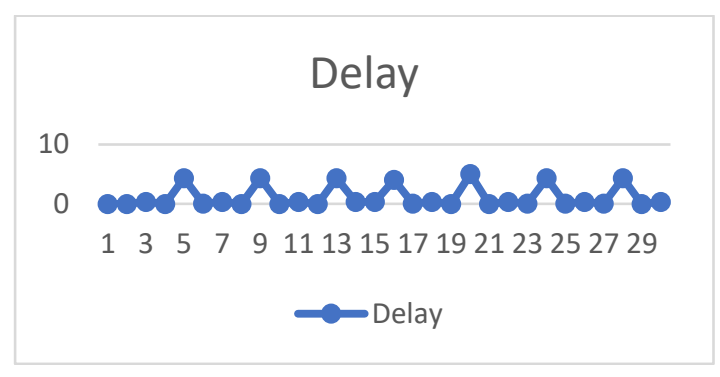

Dari gambar dapat dilihat juga bahwa perubahan pada saat pengambilan data mempengaruhi delay pengiriman data dari server ke client.

\section{KESIMPULAN}

Berdasarkan perancangan alat dan hasil pengujian yang dilakukan pada penelitian ini dengan judul dapat disimpulkan bahwa: Dolomit berpengaruh terhadap stabilitas tanah bekas timbunan sampah dengan indicator sensor $\mathrm{pH}$ dan sensor EC fungsi dari dolomite sendiri digunakan untuk meningkatkan $\mathrm{pH}$ dan EC pada tanah. Disini tanah yang berdolomite lebih banyak pH dan EC nya akan lebih besar dari pada tanah yang berdolomite lebih sedikit . Perbandingan kapur dolomit terhadap tanah sampah menghasilkan kadar $\mathrm{pH}$ yang meningkat dengan nilai 4.5 menjadi 7.5, begitu juga dengan EC nilai awal nya 250 $\mu \mathrm{s} / \mathrm{cm}$ menjadi $400 \mu \mathrm{s} / \mathrm{cm}$. Sensor Soil EC dan suhu disini dapat mendeteksi konduktivitas tanah dengan nilai rata rata mendekati $400 \mu \mathrm{s} / \mathrm{cm}$ dan suhu rata rata mendekati $24-26^{\circ} \mathrm{C}$ dikarenakan sensor ini sudah mengkalibrasi otomatis, dan sensor $\mathrm{pH}$ dapat mendeteksi $\mathrm{pH}$ pada tanah dengan rata rata error $0 \%$. Tampilan web yang menyediakan informasi mampu diakses dengan baik dengan delay $0.1536175 \mathrm{~s}$ dan troughput $25.17 \mathrm{~Kb} / \mathrm{s}$ dan dapat dibuka menggunakan laptop maupun smartphone apapun yang memilik web didalamnya sehingga memudahkan untuk melihat konduktivitas, suhu, dan kadar $\mathrm{pH}$ pada tanah.

\section{REFERENSI}

[1] Thomas Aria Cipta, Program. Magister, Ilmu. Lingkungan,2014. Lampung, "Pencemaran Akibat Kegiatan Industri," Hal. 3, Pascasarjana Universitas Lampung .

[2] Muslimah, S.Si,M.Si, Dosen Tetap Universitas Samudra 2015"Dampak Pencemaran Tanah Dan Langkah Pencegahan,” no. 1, Hal. 1,.

[3] H. Husdi, "Monitoring Kelembaban Tanah Pertanian Menggunakan Soil Moisture Sensor Fc-28 Dan Arduino Uno“, vol. 10, no. 2, p. 237, 2018.

[4] Riry Djule, Rima, Nini Firmawati, "Rancang Bangun Prototipe Sistem Kontrol pH Tanah Untuk Tanaman Bawang Merah Menggunakan Sensor E201-C," vol. 7, no. 1, 2018 Hal. 63,

[5] Lutfiyana, Hudallah Noor, Suryanto Agus., "Rancang Bangun Alat Ukur Suhu Tanah ," vol. 9, no. 2, Hal. 80, 2017. 